\title{
Brave New World?
}

1 NZZ vom 15./16. Februar 2002, Nr. 38 S. 55.

2 Entwurf zum Opferhilfegesetz. Art. 20 (Herabsetzung und Ausschluss der Genugtuung), Punkt 4.
In Arkansas (USA) soll ein schizophren kranker Straftäter hingerichtet werden. Er beging einen Raubmord, wurde jedoch aufgrund seiner psychiatrischen Erkrankung als unzurechnungsfähig erklärt. Nun hat ein Bundesberufungsgericht die zwangsweise Behandlung mit antipsychotischen Medikamenten verfügt, damit die Zurechnungsfähigkeit wieder hergestellt und die Todesstrafe legal vollgezogen werden könne [1].

Was dieses amerikanische Bundesberufungsgericht verfügt hat, ist an Doppelzüngigkeit und Schlitzohrigkeit kaum mehr zu überbieten.

Wo bleibt da die so hoch gepriesene Menschenwürde? Ist dieses Berufungsgericht von einer ähnlichen Blindheit geschlagen wie sein US-Präsident: Beide erkennen den Balken im eigenen Auge nicht?

Aber: wenn im Entwurf zum Opferhilfegesetz unseres Landes zu lesen steht: «Es kann davon abgesehen werden, dem Opfer eine Genugtuung zuzusprechen, wenn es infolge der Straftat nicht mehr in der Lage ist, die erlittenen Beeinträchtigungen wahrzunehmen.» [2] - dann frage ich mich auch: sind bei uns ähnlich strukturierte Gesetzgeber am Werk wie in der Neuen Welt?

Hier werden nicht nur die Menschenrechte verletzt. Es kommt unüberschaubar zum Ausdruck, wie weit weg vom Menschlichen überhaupt ein scheinbar so sauberes, emotionsbefreites, wertneutrales abstrahierendes Denken führt. Das hippokratisch verankerte «nichts Menschliches ist mir fremd» muss unangetastet bleiben. Als Staatsbürgerinnen und Staatsbürger bleibt uns im Moment fast nur das Goethesche «mir graut vor dir!»

Was können wir aber als Ärztinnen und Ärzte tun? (Mir hat es beim ersten Lesen die Sprache verschlagen; allmählich finde ich sie wieder.)

Dr. Ursula Steiner-König, Vizepräsidentin der FMH 